\title{
Web-Based Letter Management Information System in East Kalimantan Plantation Department
}

\author{
Istiqomah \\ Software Engineering Technology, \\ Agricultural Polytechnic of \\ Samarinda, Samarinda, Indonesia \\ Istiqmh08@gmail.com
}

\author{
Suswanto* id \\ Software Engineering Technology, \\ Agricultural Polytechnic of \\ Samarinda, Samarinda, Indonesia \\ Suswanto.attala@gmail.com \\ *Corresponding Author
}

\author{
Ida Maratul Khamidah \\ Software Engineering Technology, \\ Agricultural Polytechnic of \\ Samarinda, Samarinda, Indonesia \\ idamaratul@gmail.com
}

Received: 2020-12-01; Revised: 2021-05-22; Accepted: 2021-05-28; Published: 2021-06-01

\begin{abstract}
The constraints that exist in a system that is run manually, include the large amount of data that must be processed, the complexity in processing data, the limited time used in processing data, and various types of data. Likewise, in an office of the Plantation Service in East Kalimantan Province, processing correspondence is still done manually. This application uses a system by entering the type of letter to find a list of incoming and outgoing mail to make it easier for operators at the Plantation Service in East Kalimantan Province. In this program, the operator must enter first to access data from incoming messages and announcements. Therefore, this application is expected to improve the previous system and make work easier so that it can shorten the time so that work efficiency increases and makes it easier for operators to process data.Based on the results of observations in the form of an interview with an employee of the Data Information Service Center (PPID) at the Plantation Office of East Kalimantan Province, it was stated that there was no system or application. Correspondence services at the Plantation Office of East Kalimantan Province have been running well, but all processes are still manual and use a lot of paper. This application is also a form of concern for paper, where paper usage is starting to be reduced. All data and documentation are presented in digital or paperless form.Referring to the results of these observations, we need a web media capable of displaying correspondence with detailed information. With this web, it is expected to be useful for employees. In addition, it can assist the East Kalimantan Provincial Plantation Office in providing correspondence information.With the Correspondence Management Information System website, it is hoped that it will be useful for employees at the Plantation Office of East Kalimantan Province in processing letter data so that they can work effectively and efficiently in the process.
\end{abstract}

Keywords- Information Systems, Correspondence, Plantation Service of East Kalimantan Province.

\section{INTRODUCTION}

Information technology in the current era can make people interested in creating new things so that they can be more useful in the future. There are various ways and efforts that can be made to achieve this. One example of the use of technology today is computers. Computers are no longer something new to the wearer. Various functions of using computers in various ways such as processing data, doing mathematical calculations and so on. The use of computers is not only limited to data processing but is also used as a solution to problems that are obtained such as information systems that are very useful for us(Kristanto, 2014).

Making changes and breakthroughs in accordance with technological advances to fulfill existing tasks, in order to provide more adequate services. Data processing for incoming and outgoing mail in the administration section still uses manual methods for data entry. Therefore, efforts are being made to process data for incoming and outgoing mail to be operated using a computer device through a Web-based application system, using a computer to input data for incoming and outgoing mail. So that the information system plays an important role in managing the correspondence of the existing in a province such as East Kalimantan (Jogiyanto \& Wursanto, 2014).

The constraints that exist in a system that is run manually, include the large amount of data that must be processed, the complexity in processing data, the limited time used in processing data, and various types of data. Likewise, in an office of the Plantation Service in East Kalimantan Province, processing correspondence is still done manually. This application uses a system by entering the type of letter to find a list of incoming and outgoing mail to make it easier for operators at the Plantation Service in East Kalimantan Province. In this program, the operator must enter first to access data from incoming messages and announcements. Therefore, this application is expected to improve the previous system and make work easier so that it can shorten the time so 
that work efficiency increases and makes it easier for operators to process data.

Based on the description in the background section, a problem formula can be taken as follows:

1. How to design a web-based correspondence management information system at the Plantation Office of East Kalimantan Province that is able to organize and process letters such as selecting types of letters, creating letter reports archives and downloading letters?

2. How do you make this correspondence information system application so that it can be used and help complete tasks that are in the Plantation Office?

The limitations of the problems in this study include:

1. The research was conducted at the Plantation Office of East Kalimantan Province.

2. The object of the research is correspondence at the Plantation Service of East Kalimantan Province.

The goals and results to be achieved in this research are:

1. Assist in processing and compiling data for incoming and outgoing mail.

2. Make it easier for operators to search for letter data, both new and old letters.

3. In order to make it easier to carry out the process of making correspondence, so that the process is well controlled.

4. Can be used and used by the office as a basic reference for improving the correspondence system that is currently running.

\section{LITERATURE REVIEW}

\section{A. Study of literature}

Research conducted by (Jogiyanto et al., 2014), entitled Designing Information Systems Management of Incoming and Outgoing Mail at MTs Guppi Jetiskidul. This application aims to be able to manage incoming and outgoing mail in a computerized manner, find out the weaknesses of the running system, and fix the weaknesses of the running system. The weakness of the old system condition is that there is no special application for managing incoming and outgoing mail data, only data collection is done manually or recorded in a register book, so it has not been processed optimally, especially for searching for letters that have been issued or letters. -a letter that has already been received. The advantage of this application is that it can manage mail data, both incoming and outgoing mail so that these letters can be quickly searched anytime if needed.

Research conducted by (Celya-Kusdinar, 2014), entitled Archive Information System for Incoming and Outgoing Letters in the Organization and Empowerment Section of Regional Apparatus of the Secretariat of the City of Bandung. This application aims to fulfill and improve the system of incoming and outgoing mail in the ongoing organization and empowerment of the Bandung City Secretariat Regional Apartment. Designing incoming and outgoing mail systems, testing applications for incoming and outgoing mail systems, and implementing applications for incoming and outgoing mail systems in the organization and empowering regional apparatus of the Bandung City secretariat. The time needed to retrieve letter data is expected to be faster because of the data search facility in this information system. With this information system, it is easier and faster to record data stored in the database, so there is no need to use a ledger. With data stored in the database, it does not require too large storage space for letters and can minimize data loss and damage.

Research conducted by (Masykur et al., 2015), entitled Administration System for Web-Based Management of Incoming Mail and Outgoing Mail Archives. This application aims to build an Administrative Information System as a storage medium for incoming and outgoing letters at SMK Negeri 1 Magetan. Provides convenience in managing the archives of incoming and outgoing mail and easiness in finding archives for incoming and outgoing mail. With a website-based administrative system for managing incoming and outgoing mail archives, it can make it easier for employees to easily manage letter archives from year to year and from damage to archives. The administration system for managing incoming and outgoing mail makes it easier to find mail archives accurately, easily and efficiently.

Research conducted by (Defi-Siska, 2015), entitled Information System for Archiving Incoming and Outgoing Letters at the Pringkulu District Office. This application aims to produce an information system for archiving incoming and outgoing mail at the Pringkulu District Office. This information system can only be used to assist the process of filing incoming and outgoing mail. By using this information system for archiving incoming and outgoing mail, the data search process for incoming and outgoing mail will be fast because the data is stored safely and structurally and there is no longer any delay in data retrieval. With the system analysis of incoming and outgoing mail which is computerized so that it can increase work productivity, especially in terms of the process of recording incoming and outgoing mail and making reports will be fast and accurate.

Research conducted by (Sari 2018), entitled Archiving Information System for Incoming and Outgoing Letters at Notary Debora Ekawati Lukman Dadali, SH. This application aims to help facilitate employees in filing at the notary office of Debora Ekawati Lukman Dadali, SH. Adding insights on how to build and implement an information system at the notary office of Debora Ekawati Lukman Dadali, SH. Providing fast, precise, accurate information regarding the data and reports needed. The benefit of this research is that it provides convenience in the process and archiving of incoming and outgoing mail on time according to the problems and objectives set. Computer-based information system for archiving incoming and outgoing mail can make it easier to provide information to users. Computer-based information system for archiving incoming and outgoing mail is expected to facilitate the search for incoming and outgoing mail data, as well as in presenting the resulting information in a more timely and timely manner. Computer-based information system for archiving 
incoming and outgoing mail can simplify the processing of incoming and outgoing mail data, filing and preparing reports.

\section{B. Theory Basis}

\section{System}

The origin of the word system comes from the Latin systema and the Greek sustema. The definition of a system is a unit consisting of components or elements that are linked together to facilitate the flow of information, material or energy to achieve a goal. Or it can also be said that the notion of a system is a set of elements / elements that are interrelated and influence each other in carrying out joint activities to achieve a goal (Palit et al., 2015).

2. Information

Information is data that is processed through a model into information, the recipient then receives the information, makes decisions based on that information and takes action, which means producing another action that will make some data back. The data will be recaptured as input, processed again through a model and so on which is a cycle (Palit et al., 2015).

3. Information System

Information system is a system that provides information for management in making decisions and also for running company operations, where the system is a combination of people, information technology and organized procedures. Usually a company or business entity provides some kind of information that is useful for management (Junus, 2018).

4. Archives

Archives are records of activities or events in various forms and media in accordance with developments in information and communication technology that are made and accepted by state institutions, regional governments, state institutions, regional governments, educational institutions, companies, political organizations, community organizations, and individuals in their implementation. Life in society, nation and state (Imasita et al., 2015).

5. Incoming Leters

Incoming letters are letters received by an organization or company originating from individuals or organizations. Management of incoming mail consists of receiving letters, sorting, and recording, directing, delivering and storing letters (Subekti, 2015).

6. Outgoing Letter

Outgoing letter is a letter issued or prepared by a company or organization to be sent to another party. Its management consists of dictating letters, taking notes on an agenda book, typing concepts, asking for signatures from the directors, checking letters and distributing letters (Subekti, 2015).

\section{Hypertext Markup Language}

Hypertext Markup Language or commonly called HTML is a set of symbols or tags written in a file used to display web browser pages. However, the general meaning is a web programming language that has certain syntax or rules in writing codes, so that the browser can display information by reading HTML codes (Fajar Nurhfi Ilsan 2014).

8. Flowchart

Flowchart is a graphic depiction of the steps and sequence of procedures of a program. Flowcharts help analysis and programmers to solve problems into smaller segments and help in analyzing other alternatives in operation. Flowcharts usually make it easier to solve a problem, especially problems that need to be studied and evaluated further. According to (Setiawan, 2011), a flowchart is a form of image or diagram that has a flow in one or two sequential directions. Flowcharts are used to represent and design programs. Therefore flowcharts must be able to represent components in a programming language.

9. Context Diagram

Context diagram in designing an information system which is a tool in designing in general the design that will be made which aims to determine the state of the system to be built (Abdullah et al, 2015).

10. Entity Relationship Diagram

This method was developed by Chen in 1976. It is a graphic technique used to describe the database schema. ERD illustrates the logical structure of the database by paying attention to the entities in the system (Abdullah, 2015).

11. Entity Relationship Diagram

Xampp is free software that supports multiple operating systems. Xampp is a compilation of several programs. Its function is as a stand-alone server (localhost) which consists of the Apache HTTP Server program, MySQL database and a language translator written in the PHP and Perl programming languages. The name Xampp stands for $\mathrm{X}$ (any four operating systems), Apache, MySQL, PHP and Perl. This program is available under the GNU General Public License and is free. Xampp is an easy-to-use web server that can serve dynamic web page displays (Setyaningsih, 2017).

12. MYSQL

MySQL is a multithreaded and multi-user SQL database management system software or DBMS. MySQL is very popular with web developers (web developers) because it has speed and small size making MySQL more ideal for websites coupled with the fact that MySQL is open source which means free (Abdullah, 2015). 


\section{RESEARCH METHODS}

\section{A. Time and Place}

This research was conducted at the Plantation Office of East Kalimantan Province, which is located at Jalan MT. Haryono, Air Putih, Kec. Samarinda Ulu, Kota Samarinda, East Kalimantan 75243 as places to be studied. The manufacture and development of the system will be carried out at the Software Engineering Laboratory in the Software Engineering Technology Study Program, Department of Agriculture Management, State Agricultural Polytechnic of Samarinda. This research time took 8 months, from October 2019 to October 2020, including the preparation of proposals, data collection, application development, and report preparation.

\section{B. Tools and Materials}

The tools used in the thesis proposal for the Web-based Management Information System at the Plantation Service of East Kalimantan Province are writing tools, are used to record all important information related to the thesis title

1. ASUS laptop (4GB Ram, Intel Core i3)

2. Windows 10 Operating System

3. Visual Studio Code

4. XAMPP

5. MySQL

6. Microsoft Word

7. Visio 2013

\section{Research Procedures}

The stages of the research procedure used the waterfall model. This model takes a systematic or sequential approach in building a flow of research procedures. To know clearly shown in Picture 1.

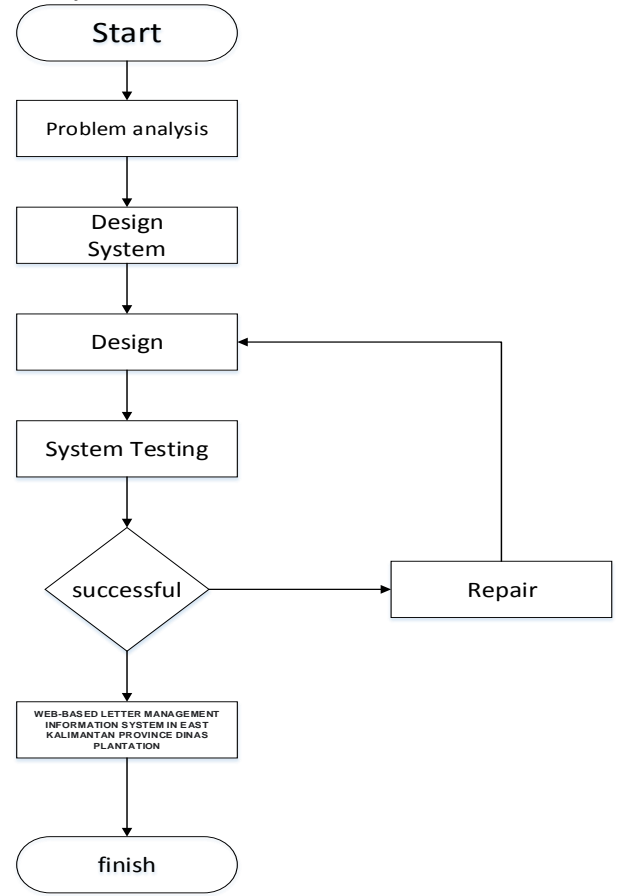

Picture 1. Flowchart of Research Procedures
1. Analysis

This analysis is used to analyze the company's old system and describe the needs of the Plantation Agency. This stage will make direct observations or observations of the company's operational activities related to data processing at the Plantation Service, to build a Correspondence Management Information System application with variable limitations at the functional level which includes incoming mail data, outgoing mail data, letter filing, and disposing.

2. System planning

After the system design. Next is the process of creating programs for applications. This stage is the process of building a system that can solve problems and process the data that has been collected from observations and interviews. The process from the results of the system design that has been created is then implemented.

3. System Creation

Design Systemhelps in hardware (hardware) and systems requirements and also helps in defining the system architecture overall.

4. Testing

After the system has been successfully created, the correspondence information system is tested, by testing the system whether it is running well or not, and can produce results according to the needs of the Plantation Office.Research Data Processing Techniques Research.

\section{System Design}

1. DFD (Data Flow Diagram) Level 0

DFD level 0 is a diagram that only displays and describes the data flow mechanism of a system in general. At DFD level 0, there are 3 entities, namely the operator, the Head of Service, and PPID. Following is DFD (Data Flow Diagram) level 0, can be seen in Picture 2.

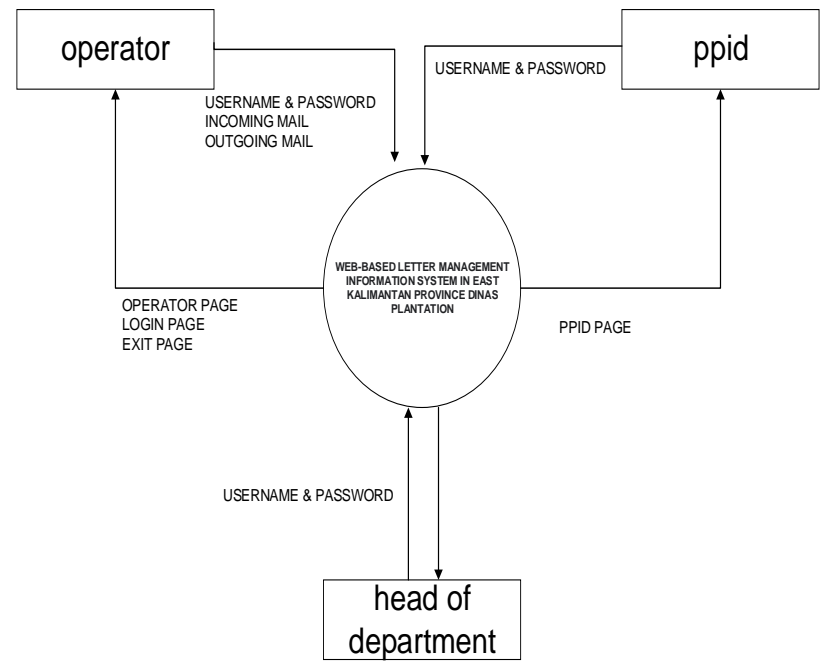

Picture 2. DFD Level 0 
2. DFD (Data Flow Diagram) Level 1

DFD level 1 is a diagram that displays a system mechanism on data flow in more detail which functions to describe the process directly on the level 0 diagram.In DFD level 1, it is explained that the admin can log in to enter the application and manage data such as editing data, adding data and delete data. This application also provides information such as incoming mail, outgoing mail and other information, users search for letter information, and this correspondence information system application provides information to users. The following is DFD (Data Flow Diagram) level 1, can be seen in Picture 3.

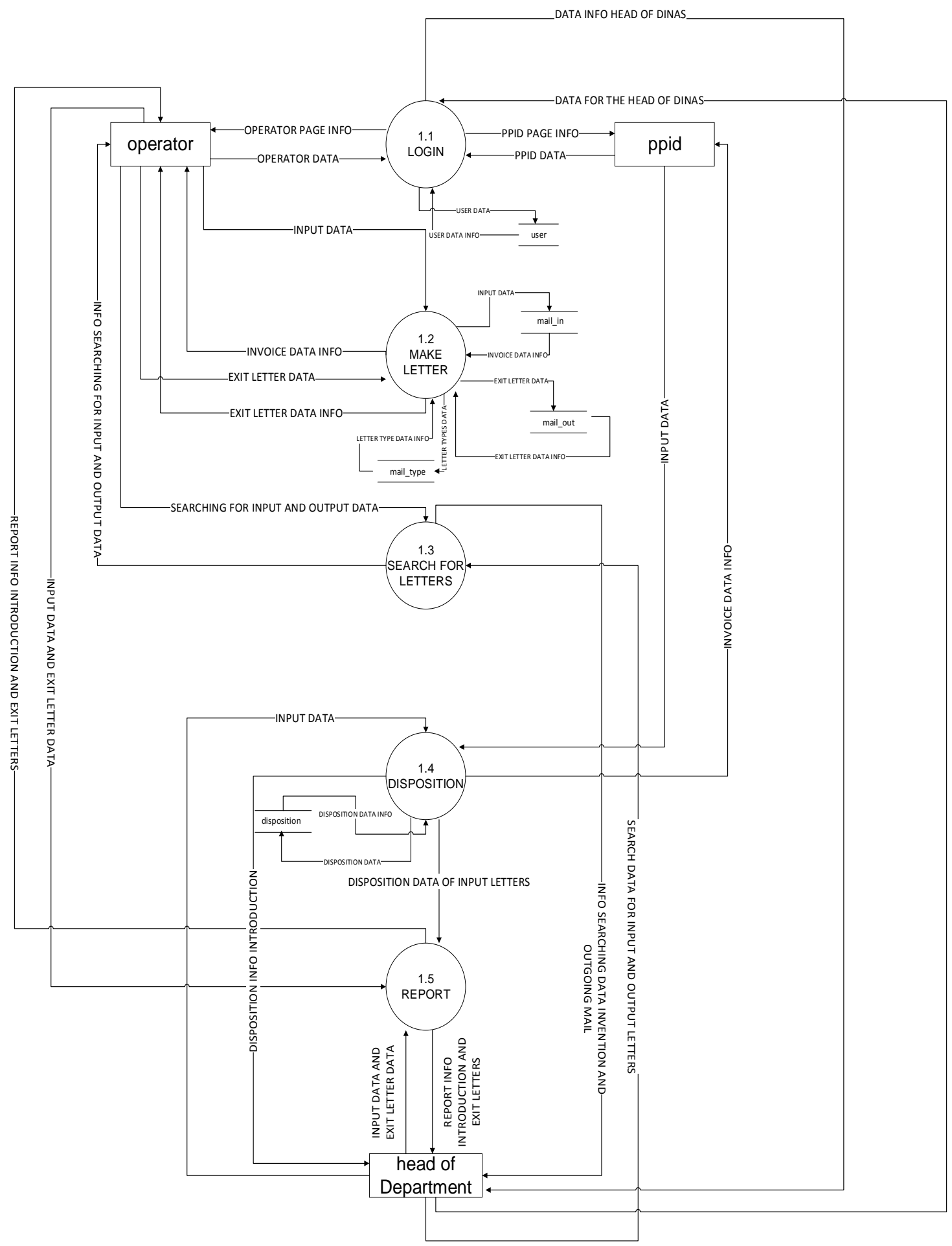

Picture 3. DFD Level 1 


\section{RESULTS AND DISCUSSION}

The results of making this correspondence application are as follows:

1. Login Page

The login page for the operator, before the operator enters the dashboard page, the operator must log in by entering the correct username and password along with the choice of user level, after successful login the operator will enter the dashboard page, it can be seen in Picture 4

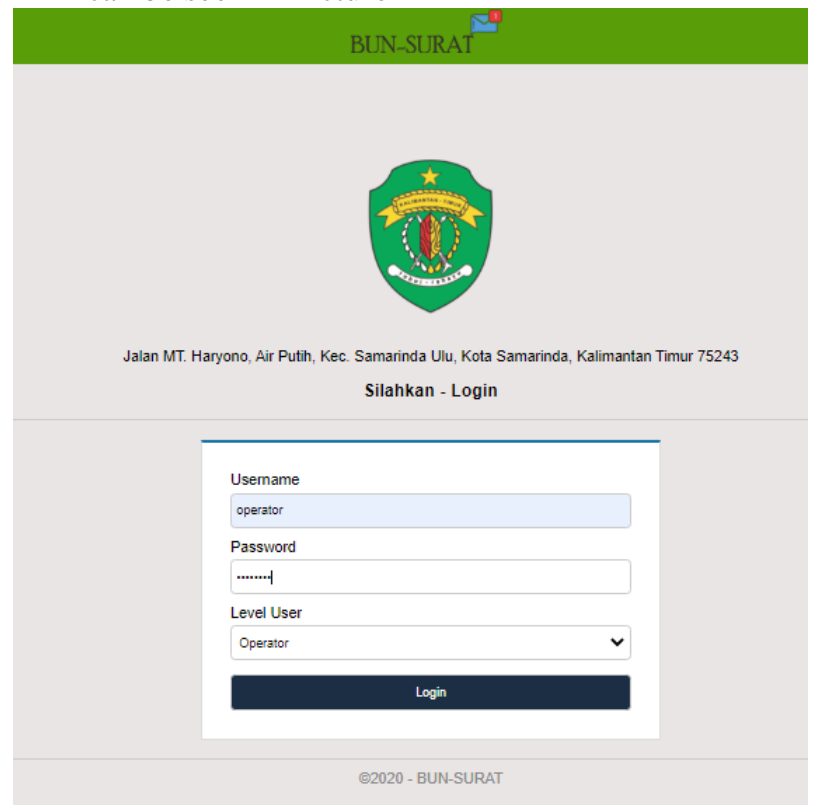

Picture 4. Login Page

2. Dashboard Page

After logging in, the system will display a dashboard page for the operator, the dashboard page has several menus, which can be seen in Picture 5.

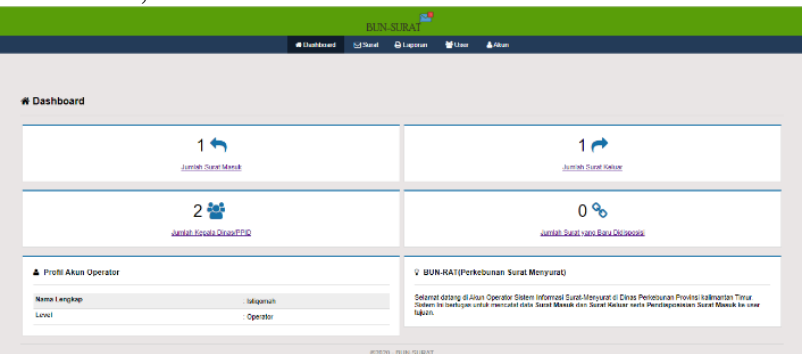

Picture 5. Dashboard Page

3. Incoming Mail Page

In Picture 6 is an incoming mail page that functions to display incoming mail data, add incoming mail, and search.

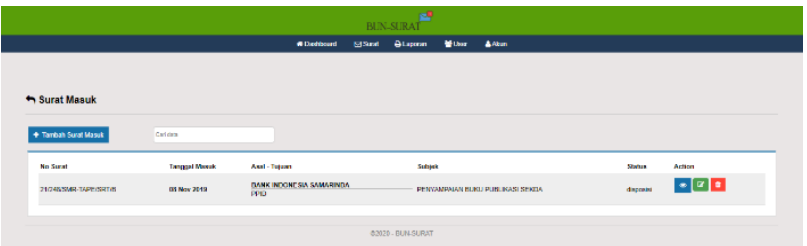

Picture 6. Incoming Mail Page
4. Outgoing Mail Page

In Picture 7 is the outgoing mail page which functions to display outgoing mail data, add outgoing mail, and search.

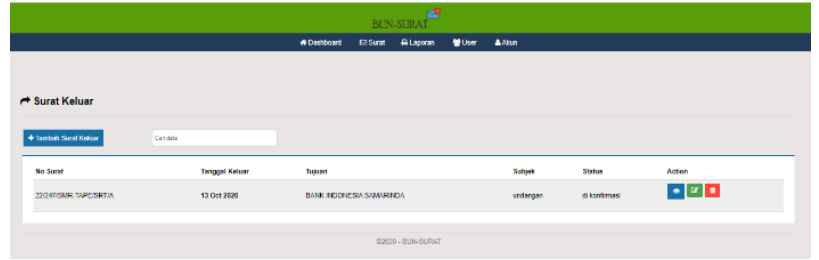

Picture 7. Outgoing Mail Page

5. Letter Disposition Page

The letter disposition page that is on the Operator is a page that functions to print the disposition that has been addressed to the destination user, it can be seen in Picture 8.

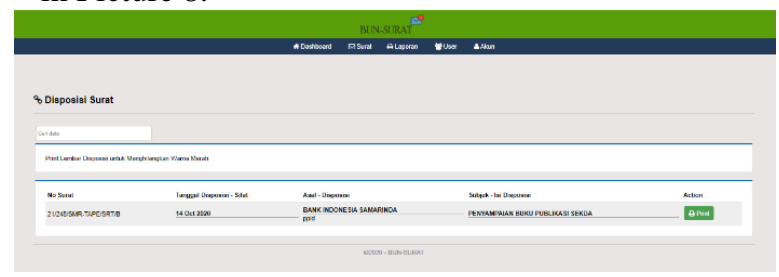

Picture 8. Letter Disposition Page

6. Incoming Mail Report Page

The incoming mail report page on the Operator is a page that functions to view all incoming mail reports and print incoming mail reports, can be seen in Picture 9.

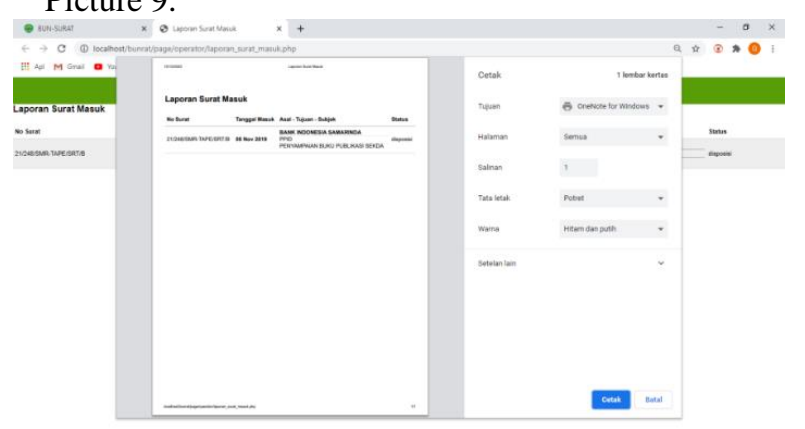

Picture 9. Incoming Mail Report Page

7. Outgoing Mail Report Page

The outgoing mail report page on the Operator is a page that functions to view all outgoing mail reports and print outgoing mail reports, can be seen in Picture 10.

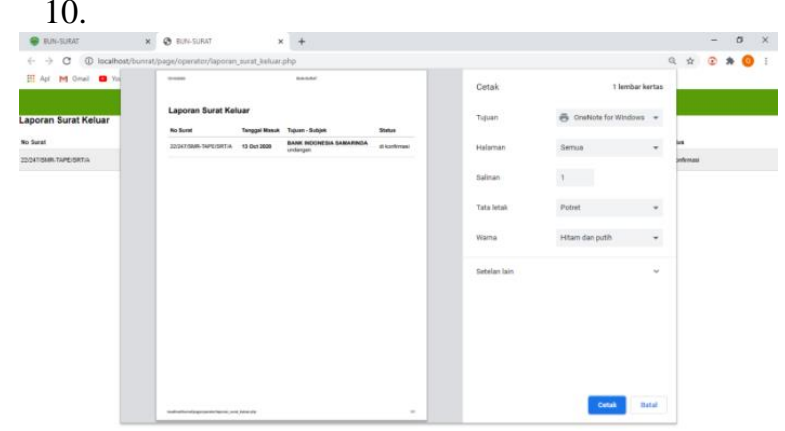

Picture 10. Outgoing Mail Report Page 
8. Respondent Testing Results

The results of respondents' testing of the use of theapplication can be seen in table 1 .

Table 1. Respondent testing results

\begin{tabular}{|c|c|c|c|c|c|}
\hline \multirow[b]{2}{*}{ Question } & \multicolumn{5}{|c|}{ Score } \\
\hline & $\begin{array}{l}\text { Strongly } \\
\text { Agree }\end{array}$ & Agree & Average & Disagree & $\begin{array}{l}\text { Strongly } \\
\text { Agree }\end{array}$ \\
\hline $\begin{array}{l}\text { Is the design or appearance of this } \\
\text { web application system attractive? }\end{array}$ & $37.5 \%$ & $61.3 \%$ & $3.1 \%$ & $0 \%$ & $0 \%$ \\
\hline $\begin{array}{l}\text { Is the application logo that was } \\
\text { designed attractive? }\end{array}$ & $18.8 \%$ & $78.1 \%$ & $3.1 \%$ & $0 \%$ & $0 \%$ \\
\hline $\begin{array}{l}\text { Is the color selection in the web } \\
\text { design appropriate? }\end{array}$ & $21.9 \%$ & $78.1 \%$ & $0 \%$ & $0 \%$ & $0 \%$ \\
\hline $\begin{array}{l}\text { Are the features provided in the } \\
\text { web application easy to } \\
\text { understand? }\end{array}$ & $21,9 \%$ & $21,9 \%$ & $0 \%$ & $0 \%$ & $0 \%$ \\
\hline $\begin{array}{l}\text { Are the buttons on the system } \\
\text { running properly? }\end{array}$ & $18,8 \%$ & $81.3 \%$ & $0 \%$ & $0 \%$ & $0 \%$ \\
\hline $\begin{array}{l}\text { Is the disposition / follow-up } \\
\text { letter easy to understand? }\end{array}$ & $18.8 \%$ & $78.1 \%$ & $3.1 \%$ & $0 \%$ & $0 \%$ \\
\hline Average & $22.95 \%$ & $75.83 \%$ & $1.55 \%$ & $0 \%$ & $0 \%$ \\
\hline
\end{tabular}

Based on table 7 , the respondent's responses are 32 people, from the results of trials that have been carried out on the web-based application of the correspondence management information system at the East Kalimantan Provincial Plantation Office, the web-based results obtained the highest value, namely $75.83 \%$ with agreed answers (S), and the percentage of $22.95 \%$ with the answers strongly agree (SS).

\section{CONCLUSIONS}

Based on the results of the research and discussion that has been carried out, it is concluded that in making a correspondence management information system application has obtained results, namely that it can provide information about correspondence in the Plantation Service. Based on the responses of respondents from the test results regarding this application has the highest value of $75.83 \%$ with the answer Agree (S), a value of $22.95 \%$ with the answer Strongly Agree (SS), a value of $1.55 \%$ with an answer of Enough (C), and the lowest value of $0 \%$ with answers Disagree (TS) $0 \%$ and Strongly Disagree (STS). Thus the application tested is suitable and suitable for use for the correspondence information system at the plantation office. This application is expected to be developed with a more attractive appearance. Can improve the lack of correspondence that exists in the Plantation Office of East Kalimantan Province so that the system can be used better.

\section{REFERENCES}

Kristanto, A. 2004. Software Engineering (Basic Concepts). Yogyakarta: GAVA MEDIA.

Celya, I and Daniastari K. 2014. "Information System Archives of Incoming Letters And Outgoing Letters in the Organization and Empowerment Section of
Regional Apparatus Secretariat of the City of Bandung.".

Fajar, NI. 2014. "Information System for Incoming and Outgoing Letters of the Jambi Province Election Supervisory Agency." Information System for Incoming and Outgoing Letters of the 2014 Jambi Provincial Election Supervisory Agency (June): 12. doi: 10.1038 / $132817 \mathrm{a} 0$.

Jogiyanto, K and Wursanto. 2014. "Designing Information System Management of Incoming and Outgoing Mail at MTs Guppi Jetiskidu." IJNS Indonesian Journal on Networking and Security 3 (4): 119-44.

Jogiyanto, K and Wursanto. 2014. "Designing Information System Management of Incoming and Outgoing Mail at MTs Guppi Jetiskidu." IJNS Indonesian Journal on Networking and Security 3 (4): 119-44.Dahlan Abdullah. 2015. "Designing a Web-Based Data Collection Information System for Students at Darul Yatama Islamic Junior High School." IJNS - Indonesian Journal on Networking and Security 4 (1): 39-44.

Defi, A and Iriani S. 2015. "Information System for Archiving Incoming and Outgoing Letters at the Pringkuku District Office." Indonesian Journal on Networking and Security (24): 1-4.

Palit, RV, Yaulie DYR, and Lumenta ASM. 2015. "Design of a Web-Based Church Financial Information System in the Bukit Moria Malalayang GMIM Congregation." E-JOURNAL OF ELECTRO AND COMPUTER ENGINEERING 4 (7): $1-7$.

Imasita, AG and Hirman. 2015. "Development of WebBased Archive Management Model (Letters) and Government Documents in Sidrap Regency Government Office, South Sulawesi Province. Development of Web Based Archive and Document Administration Model in Government 
Office of Sidrap Regency." Science Journal IV (2): 196-204.

Masykur, F, Ibn Makruf, and Pandu, A. 2015. "WebBased Administration System for Archive Management of Incoming and Outgoing Mail." Indonesian Journal on Networking and Security 4 (3): $1-7$.

Subekti, A. 2015. "Management of Incoming and Outgoing Mail at Jogyatronik Mall Yogyakarta." Ekp 13 (3): 1576-80.

Setyaningsih, S. 2017. "Web-Based Computerized Data System for Two-Wheeled Vehicle Parts." International Journal of Engineering \& Technology 1-2: 46-.

Junus, M. 2018. "Information System for Web-Based Management of Incoming \& Outgoing Letters of Electrical Engineering Department Through Networks." Journal of ELTEK 16: 18-32.

Sari, PI. 2018. "Information System for Archiving Incoming and Outgoing Letters IN Notary Debora Ekawati Lukman Dadali, SH." Information System for Archiving Incoming and Outgoing Letters at Notary Debora Ekawati Lukman Dadali, SH. 